Research Article

\title{
Mechanical Modification of Resin Capsules by Adding Steel Particles
}

\author{
Xiaowei Feng, ${ }^{1}$ Fei Xue $\mathbb{D}^{2},{ }^{2}$ Tongyang Zhao, ${ }^{3}$ and Wenjie Jiang ${ }^{2}$ \\ ${ }^{1}$ State Key Laboratory of Coal Resources and Safe Mining, School of Mines, China University of Mining and Technology, \\ Xuzhou 221116, China \\ ${ }^{2}$ College of Civil Engineering, Key Laboratory of Rock Mechanics and Geohazards of Zhejiang Province, Shaoxing University, \\ Shaoxing 312000, China \\ ${ }^{3}$ State Key Laboratory of Mining Disaster Prevention and Control, Shandong University of Science and Technology, \\ Qingdao 266590, China
}

Correspondence should be addressed to Fei Xue; kdckxf@126.com

Received 9 December 2020; Revised 4 February 2021; Accepted 16 June 2021; Published 25 June 2021

Academic Editor: Nur Izzi Md. Yusoff

Copyright ( 12021 Xiaowei Feng et al. This is an open access article distributed under the Creative Commons Attribution License, which permits unrestricted use, distribution, and reproduction in any medium, provided the original work is properly cited.

Five kinds of steel particles with sizes ranging from $0.6 \mathrm{~mm}$ to $2.2 \mathrm{~mm}$ with increments of $0.4 \mathrm{~mm}$ were mixed with mining resin materials, and the mixing ratio of the particles was also varied. By using this approach, the film gloving problem of coal mine bolting should be effectively solved due to the shredding effects of the particles during bolt rotation. The premise is that the mechanical behavior should not be weakened under such conditions. A total of 47 standard cylindrical specimens were manually prepared, which included pure resin specimens and specimens containing particles with different sizes and weights. First, the homogeneity of a prepared standard specimen was verified by computed tomography (CT) scanning technology. Second, the mechanical improvements provided by each type of particle were evaluated. Thirdly, the effectiveness of both the particle weight and particle size was comprehensively discussed, and the eventual recommendation was to set for the particle size and weight as $1.4 \mathrm{~mm}$ and $40 \mathrm{~g}$, respectively, and the particles weight percentage was $7.27 \%$. Finally, the failure patterns for all specimens were collected and comprehensively compared. Additionally, pullout tests were carried out to vindicate the recommended particle size and weight.

\section{Introduction}

A bolting system consists of a rebar inserted into a borehole and is simultaneously bonded with a rock mass by using a specific bonding material. Through the use of a bolting system, the deformation of a rock mass can be restrained, or a loose rock mass can be reinforced; eventually, the potential instabilities of rock masses can be largely prevented [1-3]. Bolting technologies are widely used in geotechnical and mining areas, and to the best of the author's knowledge, bolting technology emerged over a hundred years ago in a slate quarry in North Wales in 1872 [4].

Currently, a bolting system uses either a resin cartridge or cementitious material to serve as an intermediary that can bond a bolt to the inner wall of a borehole. Consider that the reinforcement provided by the bolt can be classified as follows: (1) Continuously Mechanically Coupled (CMC); (2) Continuously Frictionally Coupled (CFC); and (3) Discretely Mechanically or Frictionally Coupled (DMFC) [5]. The classification is based on how the element load is transferred to the rock, and then the resin-bonded bolts belong to the CMC system. Nowadays, two-part polyester resin cartridges are extremely popular, especially in coal mines, because this resin system can achieve fantastic controlling effects of rock deformation when the resin cooperates appropriately with bolts and boreholes. The most obvious advantage of a resin cartridge is its fastsetting property, by which the fastest resin can set in less than or equal to 30 seconds [6]. Then, a rock mass can be reinforced immediately after excavation, which is 
particularly beneficial to the overall stability of an underground excavation. Additionally, the high early strength achieved by the resin is another advantage that can provide sufficient supporting effects to a rock mass, which is far beyond the corresponding property of a cementitious material.

Nevertheless, resin-based bolting systems still face challenges in practical applications. One noticeable problem is gloving, which is a phenomenon where the plastic cartridge of a resin capsule either partially or completely encases a certain length of a bolt, typically with a combination of mixed and unmixed resin filler and catalyst remaining within the cartridge $[7,8]$. Gloving often leads to poor bearing strength in a bolting system due to the mixed or unbonded section along the bolt; as a result, the bolting system tends to exhibit premature failure. As early as 1987, Pettibone's work indicated that resin properties alone could dramatically alter the extent of gloving [9]. In 2004, tests conducted by Campbell, Mould, and MacGregor testified that chamfered bolts, sinusoidal bolts, and offset nuts can reduce gloving and give the best results [10]. In 2005, Pastars and MacGregor concluded that the simulated gloved bolts provided only $10 \%$ of the load transfer of the nongloved test cases. In the same year, Compton and Oyler argued that there was no reduction in bond strength from gloving based on a comparison of standard $300 \mathrm{~mm}$ short encapsulation pull tests (SEPTs) and overcoring standard bolt pull tests.

More recently, in 2012, Peter Craig performed extensive in situ tests and indicated that SEPTs of gloved and nongloved bolts produced similar bond strength results; also, gloving could only be significantly reduced by a modified bolt end that nearly contacted the side of the bolt hole [11]. In 2016 2017, Ma et al. and Aziz et al. noticed that the top parts of most bolts had the least bond strength due to film gloving and unmixed resin, and these authors proposed an overdrilled hole installation since it can mitigate capsule film gloving in the tops of bolts $[12,13]$.

In view of the short survey above, the main solutions for reducing gloving include improving the resin properties, modifying the bolt end, and overdrilling. By adding steel particles to resin, the mechanical properties of resin could be improved [14], and more importantly, all the gloving problems could also be simultaneously reduced due to the shredding effect during bolt installation process [15]. This work uses the following two guidelines, leaving opportunities for further detailed tests and verifications. (1) Steel wires that are $2 \mathrm{~mm}$ in diameter were manually cut to 2.0 3.5 mm lengths, and the effects of various diameters and lengths were unknown. (2) Only 20 40 steel particles were added into the resin for each specimen, and the effect of the weight ratio between steel particles and resin was unknown.

In this context, this study endeavors to investigate the effects of the size and weight of steel particles when mixed with the resin material. By adding specific steel particles into the resin, the strength of the modified resin was tested and analyzed, and the pullout tests on bolts boned by modified resin were carried out. Under the established results, possibility of adding particles to alleviate film gloving problems in actual bolting system in engineering environment could be achieved.

\section{Materials and Methods}

2.1. Brief Introduction of the Resin, Steel Particles, and Preparation Procedure. The resin capsule consisted of two separately packed internal areas and an outer packing film. One of the internal areas was filled with the resin and coagulation accelerator; the other area was filled with the curing agent. Under the rotation effect of the bolt, the film is shredded, and then these materials mix and eventually solidify in less than one minute. Solidification is extremely important to transfer the load between the bolt and rock mass; thus, tiny deformation of the rock mass can be detected and then restricted. The lengths and diameters of the resin capsules were $2300 \mathrm{~mm}$ and $50 \mathrm{~mm}$, respectively. An actual photograph of the utilized resin capsule is shown in Figure 1(a).

The steel particles adopted in this test have various sizes: $0.6 \mathrm{~mm}, 1.0 \mathrm{~mm}, 1.4 \mathrm{~mm}, 1.8 \mathrm{~mm}$, and $2.2 \mathrm{~mm}$, as shown in Figure 1(b). Considering the appropriate thickness of the annulus between the bolt and the borehole, particles with sizes greater than $2.2 \mathrm{~mm}$ were not studied. Existing studies have already shown that the annulus thickness should be $3 \sim 4 \mathrm{~mm}[16,17]$, and excessively large particles are impractical, because they greatly increase the rotation resistance during the actual installation process, which slows the drill and lowers the installation speed.

The specimen preparation requires a proper mixture between the resin and steel particles, which was accomplished by using the following procedure:

First, the exact type of steel particle was chosen, and then the specific weight was measured on an electronic scale. Second, a knife was used to slit the packing film of the resin capsule to separately gather the resin and coagulation accelerator and the curing agent. Third, the two components of the resin capsule and the steel particles were manually mixed, and then the mixture was rapidly kneaded; it is extremely important to ensure the homogeneity of the mixture. A blender was not adopted because some preliminary trials have been conducted with several kinds of blenders, which showed that the resin compound could not be homogenously mixed with the steel particles with a blender. Simultaneously, the mixture process needed to be fast because the setting time was less than or equal to one minute. This procure normally required a relatively skilled operator. Fourth, the mixture was placed inside a standard $50 \mathrm{~mm} \times 100 \mathrm{~mm}$ cylindrical mould, and the inner wall of the mould was waxed in advance for convenient demoulding. Demoulding could be performed roughly ten minutes later or after the temperature of the outer wall of the mould reached its regular temperature (the mixture process exhibited an exothermic reaction). The last step was machining. The semifinished specimens prepared in the fourth step generally could not guarantee precise standard $50 \mathrm{~mm} \times 100 \mathrm{~mm}$ cylindrical specimens; hence, the demoulded specimens were further subjected to a machining procedure. Eventually, successfully prepared 


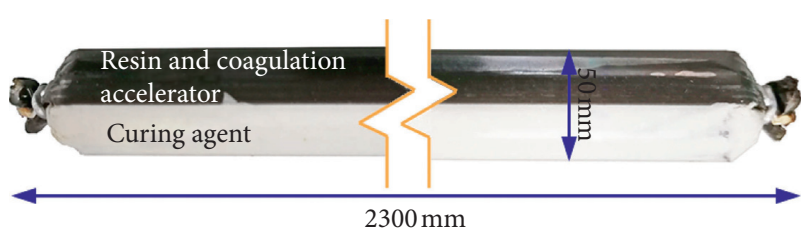

(a)
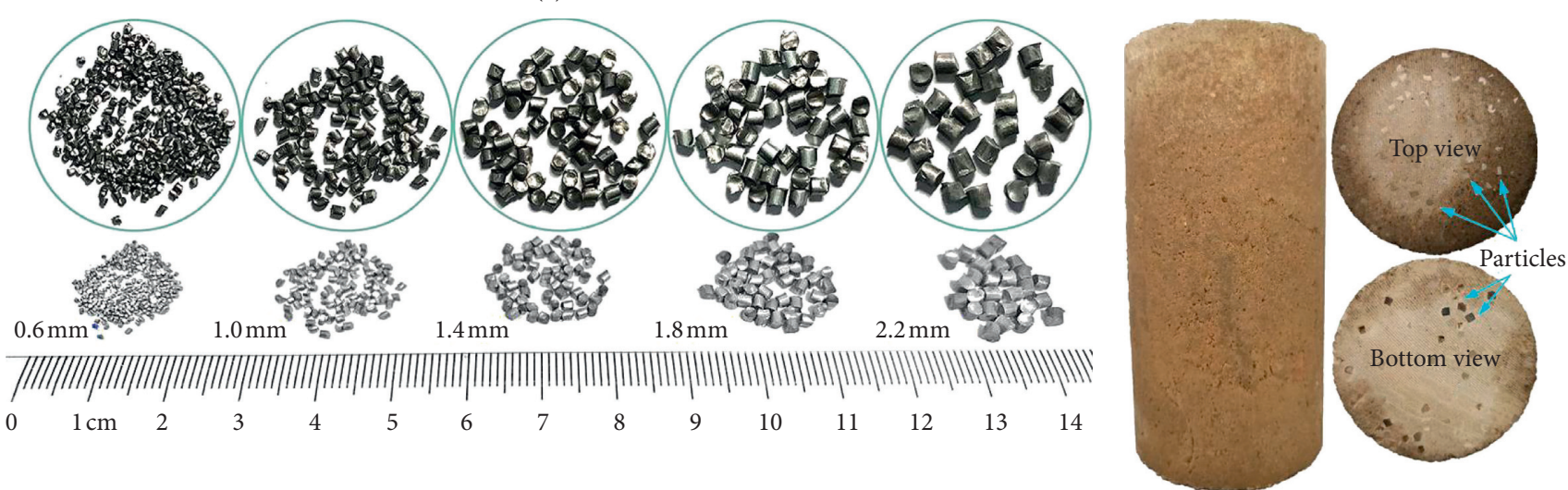

(b)

(c)

FiguRE 1: Exhibition for resin capsule, steel particles, and prepared specimen. (a) Resin capsule, (b) steel particles (note that the circled enlarged views are not scaled), and (c) a prepared specimen containing $120 \mathrm{~g}$ of $1.8 \mathrm{~mm}$ steel particles.

specimens were produced, and the top view and bottom view of a sample are shown in Figure 1(c).

By using the procedure mentioned above, a total of 47 specimens were prepared. The parameters, such as the particle size, particle weight, total weight, and density, are listed in Table 1. By careful inspection of these parameters, specimens with abnormal parameter values should be given additional attention in the analysis process, because some of them might lead to testing results that deviate from normal values.

The seventh column (ratio) in Table 1 is extremely important, because it determines how many particles were added; theoretically, this ratio should be 1 if the measured particles were completely added and mixed. Nonetheless, after the demoulding procedure, the tops and bottoms of all the specimens were further ground to meet the guidelines of the testing method outlined by the International Society of Rock Mechanics (ISRM) [18], and then some parts at the top and bottom of each specimen were removed, causing a decrease in the number of particles and lowering the ratio to less than 1 . To quantize the quality of the prepared specimens, a ratio of 0.6 was set as the critical value, and specimens with ratios less than 0.6 were regarded as abnormal, while specimens with ratios greater than 0.6 were regarded as normal. Based on this definition, the ratios of abnormal specimens are underlined in Table 1 for the convenience of mechanism interpretation in the following tests.

2.2. Testing Method. Uniaxial compressive strength (UCS) was selected as an index to evaluate the mechanical properties of the prepared specimens. It is important to note that the primary failure of resin in a practical bolting system is caused by shearing, which is the true reaction of resin within an engineering field environment; therefore, shearing is supposed to be a main factor that needs to be discussed. Nonetheless, it has been demonstrated that the UCS has a close relationship with shearing. The traditional Mohr-Coulomb shear strength criterion considers the strength to be linearly dependent on the normal stress on the shear plane [19], and the criterion for shear strength $\tau$ is $\tau=\sigma_{\mathrm{n}} \tan \phi+c$, where $c$ is the cohesion, $\sigma_{\mathrm{n}}$ is the normal stress, and $\phi$ is the internal friction angle. Therefore, the evaluation of mechanical properties based on UCS can reflect the true behavior of resin in engineering fields. Basically, a resin specimen with a high UCS also has a high shear strength, and the corresponding modified resin capsule can also produce better reinforcing effects.

The tests were conducted by using an MTS testing system (Model 64.106/64.106 E). For the technical details regarding this machine, readers can refer to the author's previous study [20]. The loading rate was $1 \mathrm{~mm} / \mathrm{min}$ with a data sampling rate of $10 \mathrm{~Hz}$, and the failure detection threshold was $70 \%$. Note that the loading rate was comparatively different from the suggested testing standard [21] because the mechanical behavior of resin is prone to plasticity, unlike the brittleness exhibited by most rock masses.

\section{Results and Discussion}

3.1. Homogeneity Detection of the Prepared Specimens. Resin has a comparatively high viscosity, which makes the manual mixture of resin difficult in some instances. As previously mentioned, the mixture of the two parts of the resin must be fast, or premature solidification can easily occur, which will lead to inhomogeneous specimens. In this 
TABLE 1: Critical parameters of the prepared specimens.

\begin{tabular}{|c|c|c|c|c|c|c|c|}
\hline No. & Particle size $(\mathrm{mm})$ & Particle weight (g) & ID & Total weight (g) & Difference $^{*} 1(\mathrm{~g})$ & Ratio*2 & Percentage $(\%)^{*} 3$ \\
\hline 1 & \multirow{3}{*}{0} & \multirow{3}{*}{0} & $\mathrm{R} 1$ & 411.11 & & & \\
\hline 2 & & & $\mathrm{R} 2$ & $416.00^{* 0}$ & - & - & - \\
\hline 3 & & & $\mathrm{R} 3$ & 417.66 & & & \\
\hline 4 & \multirow{5}{*}{0.6} & 80 & M0.6-80-1 & 464.53 & 48.53 & 0.61 & 10.45 \\
\hline 5 & & 120 & M0.6-120-1 & 471.18 & 55.18 & 0.46 & 11.71 \\
\hline 6 & & 160 & M0.6-160-1 & 515.5 & 99.50 & 0.62 & 19.30 \\
\hline 7 & & 200 & M0.6-200-1 & 531.86 & 115.86 & 0.58 & 21.78 \\
\hline 8 & & 240 & M0.6-240-1 & 555.91 & 139.91 & 0.58 & 25.17 \\
\hline 9 & \multirow{7}{*}{1} & \multirow{2}{*}{80} & M1.0-80-1 & 455.02 & 39.02 & 0.49 & 8.58 \\
\hline 10 & & & M1.0-80-2 & 470.42 & 54.42 & 0.68 & 11.57 \\
\hline 11 & & \multirow{2}{*}{120} & M1.0-120-1 & 493.08 & 77.08 & 0.64 & 15.63 \\
\hline 12 & & & M1.0-120-2 & 490.19 & 74.19 & 0.62 & 15.14 \\
\hline 13 & & \multirow{2}{*}{160} & M1.0-160-1 & 486.36 & 70.36 & 0.44 & 14.47 \\
\hline 14 & & & M1.0-160-2 & 518.79 & 102.79 & 0.64 & 19.81 \\
\hline 15 & & 200 & M1.0-200-1 & 543.81 & 127.81 & 0.64 & 23.50 \\
\hline 16 & & & M1.4-40-1 & 441.19 & 25.19 & 0.63 & 5.71 \\
\hline 17 & & 40 & M1.4-40-2 & 426.53 & 10.53 & 0.26 & 2.47 \\
\hline 18 & & & M1.4-40-3 & 448.59 & 32.59 & 0.81 & 7.27 \\
\hline 19 & & & M1.4-80-1 & 466.94 & 50.94 & 0.64 & 10.91 \\
\hline 20 & & 80 & M1.4-80-2 & 473.41 & 57.41 & 0.72 & 12.13 \\
\hline 21 & 1.4 & & M1.4-80-3 & 483.27 & 67.27 & 0.84 & 13.92 \\
\hline 22 & & & M1.4-120-1 & 511.38 & 95.38 & 0.79 & 18.65 \\
\hline 23 & & 120 & M1.4-120-2 & 495.41 & 79.41 & 0.66 & 16.03 \\
\hline 24 & & & M1.4-160-1 & 524.68 & 108.68 & 0.68 & 20.71 \\
\hline 25 & & 160 & M1.4-160-2 & 537.42 & 121.42 & 0.76 & 22.59 \\
\hline 26 & & & M1.8-40-1 & 447.69 & 31.69 & 0.79 & 7.08 \\
\hline 27 & & 40 & M1.8-40-2 & 449.63 & 33.63 & 0.84 & 7.48 \\
\hline 28 & & & M1.8-40-3 & 442.11 & 26.11 & 0.65 & 5.91 \\
\hline 29 & & & M1.8-80-1 & 476.23 & 60.23 & 0.75 & 12.65 \\
\hline 30 & & 80 & M1.8-80-2 & 479.28 & 63.28 & 0.79 & 13.20 \\
\hline 31 & 1.8 & & M1.8-80-3 & 459.45 & 43.45 & 0.54 & 9.46 \\
\hline 32 & & & M1.8-120-1 & 498.53 & 82.53 & 0.69 & 16.56 \\
\hline 33 & & 120 & M1.8-120-2 & 496.66 & 80.66 & 0.67 & 16.24 \\
\hline 34 & & & M1.8-120-3 & 498.19 & 82.19 & 0.68 & 16.50 \\
\hline 35 & & 160 & M1.8-160-1 & 526.63 & 110.63 & 0.69 & 21.01 \\
\hline 36 & & & M2.2-40-1 & 429.75 & 13.75 & 0.34 & 3.20 \\
\hline 37 & & 40 & M2.2-40-2 & 442.59 & 26.59 & 0.66 & 6.01 \\
\hline 38 & & & M2.2-40-3 & 442.32 & 26.32 & 0.66 & 5.95 \\
\hline 39 & & & M2.2-60-1 & 453.85 & 37.85 & 0.63 & 8.34 \\
\hline 40 & & 60 & M2.2-60-2 & 451.44 & 35.44 & 0.59 & 7.85 \\
\hline 41 & & & M2.2-60-3 & 471.44 & 55.44 & 0.92 & 11.76 \\
\hline 42 & 2.2 & & M2.2-80-1 & 471.21 & 55.21 & 0.69 & 11.72 \\
\hline 43 & & 80 & M2.2-80-2 & 481.79 & 65.79 & 0.82 & 13.66 \\
\hline 44 & & & M2.2-80-3 & 468.52 & 52.52 & 0.66 & 11.21 \\
\hline 45 & & & M2.2-120-1 & 502.07 & 86.07 & 0.72 & 17.14 \\
\hline 46 & & 120 & M2.2-120-2 & 508.47 & 92.47 & 0.77 & 18.19 \\
\hline 47 & & 160 & M2.2-160-1 & 497.7 & 81.70 & 0.51 & 16.42 \\
\hline
\end{tabular}

${ }^{*} 0$ Average weight of R1 3. ${ }^{*} 1$ Difference between the actual weight of each specimen and the average weight (416g) of the resin specimen; taking M1.4-40-1 as an example, the difference is $441.19-416=25.19 .{ }^{*} 2$ Ratio between the actual particle weight and theoretical particle weight; taking M1.4-40-1 as an example, the ratio is $25.19 / 40=0.63$. *3Percentage between the formerly mentioned "Difference" and "Total weight" in the table.

test, the admixture of the steel particles will make the viscosity of resin even greater; hence, a skilled preparation of the specimen is required.

It is also vital to ensure the distribution homogeneity of the particles in the prepared specimens; otherwise, pores, cracks, weak planes, or aggregations will lead to diverse testing results. In particular, the aggregation of steel particles must be avoided. To verify the homogeneity, an industrial computed tomography (CT) scan was conducted on specimen M1.8-120-1. CT-based homogeneity verification was not conducted on every specimen mainly because of cost limitations.

The scanning paths were divided into horizontal and vertical paths, and a total of 4921 image slices were obtained. Figures 2(a)-2(c) show the extraction method and corresponding images. In Figure 2(a), the distance between the 
neighboring horizontal scanning slices was $10 \mathrm{~mm}$, and the first slice was also $10 \mathrm{~mm}$ from the bottom. A total of 9 horizontal slices were then extracted and shown in Figure 2(b). Similarly, the distance between the neighboring vertical scanning slices was $5 \mathrm{~mm}$, and the first slice was also $5 \mathrm{~mm}$ to the outer margin (Figure 2(a)). A total of 9 vertical slices were extracted and are shown in Figure 2(c).

Overall, the steel particles were distributed evenly in the specimen. Additionally, conspicuous pores/cracks and weak planes were barely noticed. By further referring to the threedimensional rendered photograph in Figure 2(d), the homogeneity was further demonstrated.

3.2. Testing Results of the Pure Resin Specimens. The strengths of the resin specimens serve as a benchmark to evaluate the mechanical properties of the specimens mixed with steel particles. Figure 3 plots the curves of the three pure resin specimens (ID : R1 3). All curves exhibit a concave trend in the beginning, which is followed by a linear response; afterwards, a convex trend continues until reaching the peak value. This type of developing trend is extremely familiar in rock mechanics, and the aforementioned process can be divided into three stages: elastic stage, stable crack growth stage, and unstable crack growth stage [22].

The peak points for resin R1 3 are $(30.83,26.51),(25.19$, $24.41)$, and $(26.29,23.85)$. Some representative parameters are collected in Table 2. In Table 2, E50 represents the secant elastic modulus, which indicates the ratio between the stress and strain at $50 \%$ of the peak stress value. The average stress, average modulus, and E50 of the pure resin specimens are $24.92 \mathrm{MPa}, 0.92 \mathrm{GPa}$, and $1.08 \mathrm{GPa}$, respectively.

3.3. Testing Results for the Specimens with Particles. Figure 4 lists the strain-stress relationships for specimens mixed with particles, and the labels in the figure are sourced from Table 1. By referring to the specific parameters in Table 1, if the "Ratio" values for specimens are too small, then the results of the specimens will not be considered for plotting, for example, the ratios of $0.49,0.44$, and 0.26 for M1.0-80-1, M1.0-160-1, and M1.4-40-2, respectively.

Overall, A three-stage layout is evident in each curve. In the elastic stage, most particles suffer weak influences from rotation or shearing forces, and the bonding effects with the resin material are steady and compact. In the stable growth stage, a small number of steel particles begin to rotate and align with the direction of the inner regional shearing force, while most of the other particles can resist the rotation force and remain stationary. Accordingly, the bonding effects between some particles and the resin material may begin to deteriorate, and localized stresses tend to concentrate around the particle edges. In the unstable growth stage, the particles exhibit various kinds of movement, such as rotation, resin debonding, slippage, and distortion; the bonding effects between the particles and resin tend to be isolated or weakened. The process beyond the peak stress is mainly dominated by the movement of the macroscopic shearing planes or fracture planes.
For specimens with $0.6 \mathrm{~mm}$ particles in Figure 4(a), they exhibit greater strengths compared to those shown in Figure 3. The peak stress of M0.6-80-1 is $41.18 \mathrm{MPa}$, which is a $55.51 \%$ increase compared with the corresponding value (26.48 MPa) of R1 in Table 2. The elastic modulus of M0.6$80-1$ reaches $1.96 \mathrm{GPa}$, which is also 2.02 times the corresponding value of R2 in Table 2. This enhancement is not limited to the largest value, and the remaining specimens with particle weights ranging between $120 \mathrm{~g}$ and $240 \mathrm{~g}$ also exhibit higher strengths than the pure resin specimens. The small particles can substantially increase the mechanical ability of a resin specimen, and the most noteworthy particle modification can produce a peak stress that is $55.51 \%$ greater than that of the pure resin specimen. However, an excessively large percentage of particles in a specimen will gradually weaken the mechanical behavior.

For specimens with $1.0 \mathrm{~mm}$ particles in Figure 4(b), the results show that $1.0 \mathrm{~mm}$ particles can also bring about strengthening effects to resin specimens, and the overall strength was increased with similar values. The exact weight of particles has a limited influence on the overall mechanical behavior of the specimens, and increasing the particle addition from $80 \mathrm{~g}$ to $200 \mathrm{~g}$ barely changes the peak stress values of the specimens. Moreover, the peak stress of M1.0120-Ave. exhibits the lowest peak value among all the specimens; thus, the detailed mechanism for this finding needs to be discussed later with the complete consideration of the results from the other specimens.

For specimens with $1.4 \mathrm{~mm}$ particles in Figure 4(c), the "Ave. 40-1\&40-3" and the "Ave. 160" attain the largest peak stresses, and their strain-stress relationships are also extremely similar. With regard to the behaviors along the linear sections of the curves, the specimens mixed with $40 \mathrm{~g}$ of particles normally exhibit comparatively higher stiffness values than the other specimens. When the elastic modulus is considered, the specimens mixed with $40 \mathrm{~g}$ of particles have a greater elastic modulus than the specimens mixed with $120 \mathrm{~g}$ of particles. Based on the tests conducted herein, it is certain that the mechanical properties of resin can be improved by adding steel particles. This trend seems to have no remarkable relationship with the particle size, while the relationship with the particle weight is obvious.

For specimens with $1.8 \mathrm{~mm}$ particles in Figure 4(d), the strength expresses a decreasing trend as the particle weight increases. The peak stress decreases from $40.73 \mathrm{MPa}$ to $26.15 \mathrm{MPa}$ as the particle weight increases from $40 \mathrm{~g}$ to $160 \mathrm{~g}$, and both the elastic modulus and E50 exhibit roughly similar trends. It seems that when the particle size surpasses $1.8 \mathrm{~mm}$, the mechanical properties tend to be weakened to some extent. However, the influence of the particle weight is still prominent, as can be noticed by the decreasing trend exhibited by the mechanical properties when the particle weight increases.

For specimens with $2.2 \mathrm{~mm}$ particles in Figure 4(e), the mechanical responses of the specimens containing $40 \mathrm{~g}, 60 \mathrm{~g}$, and $80 \mathrm{~g}$ or particles are approximately the same, and this finding is especially prominent for the specimens containing $40 \mathrm{~g}$ and $80 \mathrm{~g}$ of particles. Nevertheless, the peak stresses of the specimens mixed with $120 \mathrm{~g}$ and $160 \mathrm{~g}$ of particles 


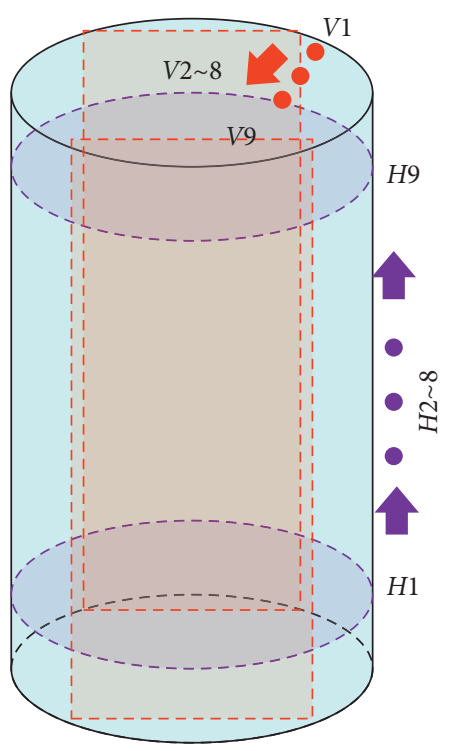

(a)

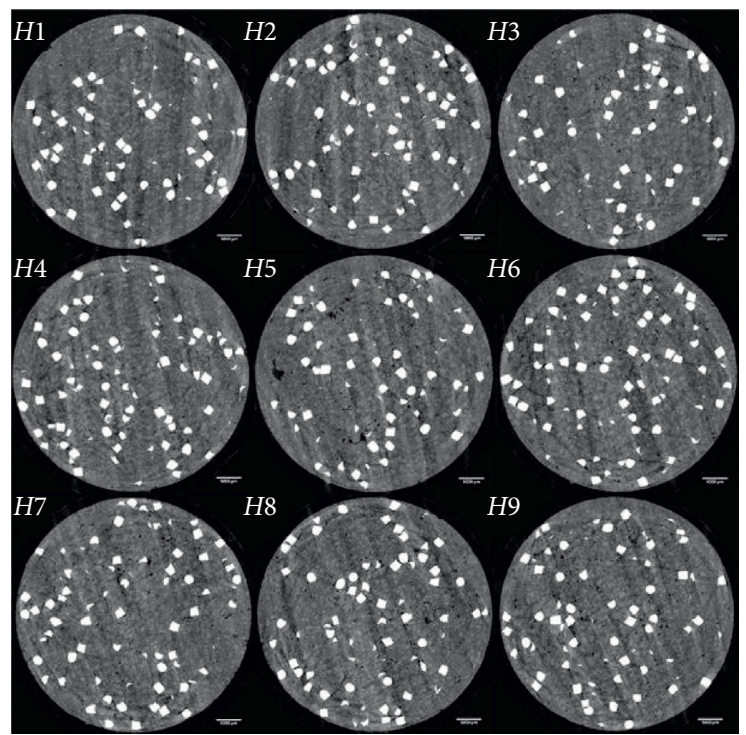

(b)

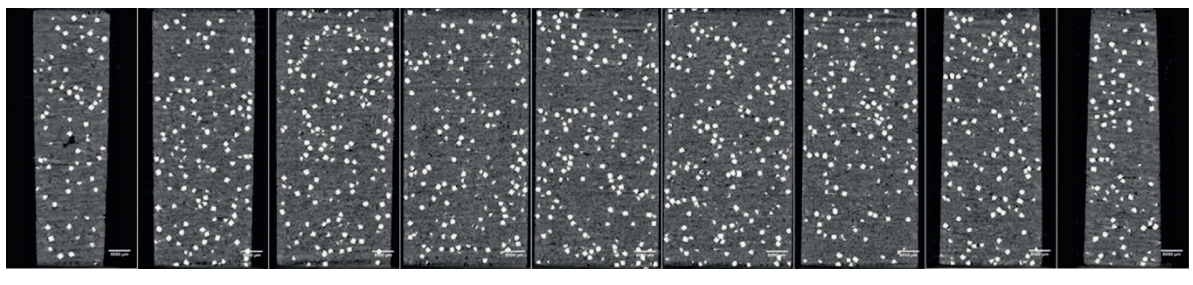

V1

V2

V3

V4

V5

V6

V7

V8

V9

(c)

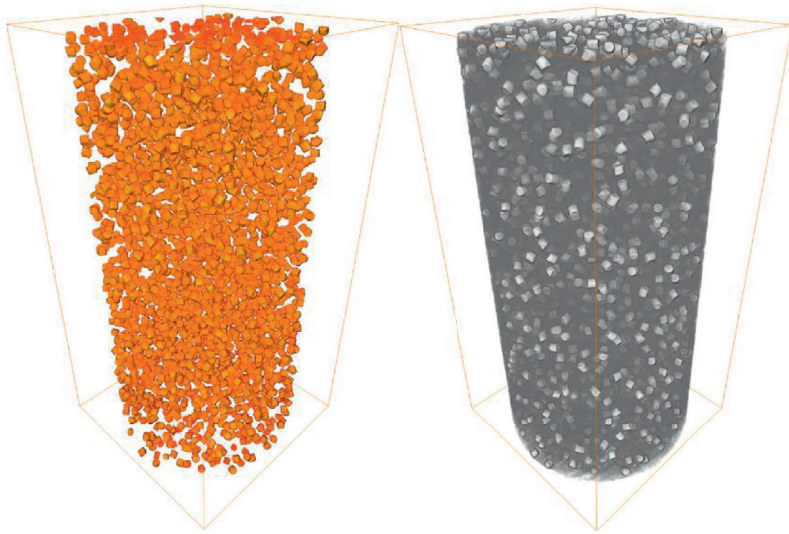

(d)

FIGURE 2: CT images for a specimen. (a) Schematic diagram for the extracted horizontal and vertical scanning slices, (b) horizontal scanning slices, (c) vertical scanning slices, and (d) three-dimensional renderings.

exhibited an evident decreasing trend. The highest E50 value was exhibited by the specimens containing $40 \mathrm{~g}$ of particles and attains the lowest E50 value exhibited by the specimens containing $160 \mathrm{~g}$ of particles. By overall comparison, it is also noticeable that increasing the particle size from $1.8 \mathrm{~mm}$ to $2.2 \mathrm{~mm}$ certainly cannot increase the strengths of the specimens. Therefore, particles larger than $1.8 \mathrm{~mm}$ will lower the strength, and this phenomenon becomes increasingly obvious when the particle size is $2.2 \mathrm{~mm}$. Additionally, the decreasing trend of strength under the effect of increasing particle weight is also prominent.
Until the analysis right here, all of the aforementioned results still lack connection to each other, and it seems that some rules that are applicable to some type of specimens are not applicable to other specimens; thus, a more comprehensive and subtle discussion is required.

\subsection{Effectiveness of the Particle Weight, Size, and Failure Patterns}

3.4.1. Effectiveness of the Particle Weight. Figure 5 lists the relationships between particle weight and peak stress for the 


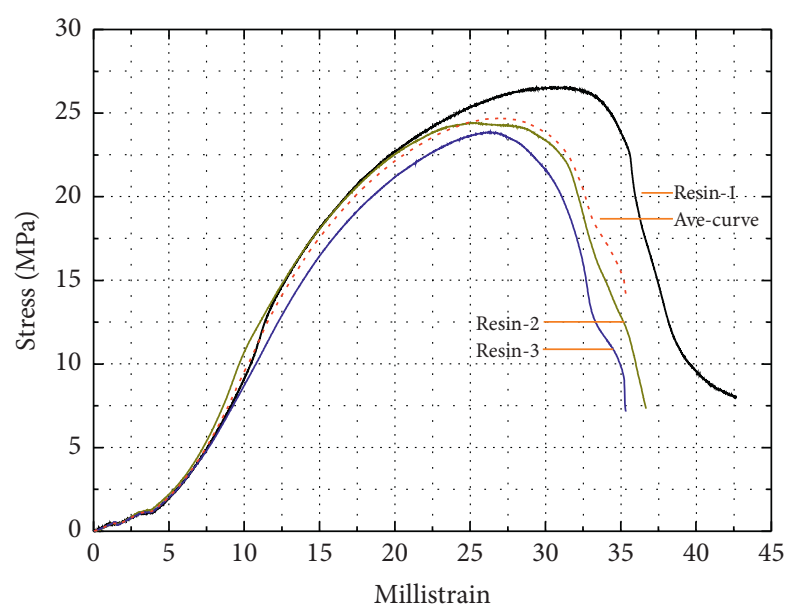

FIGURE 3: Strain-stress relationships for resin specimens R1 3.

TABLE 2: Mechanical parameters of the resin specimens.

\begin{tabular}{|c|c|c|c|c|c|c|c|c|}
\hline Specimen ID & Millistrain at peak stress & $\begin{array}{c}\text { Peak stress } \\
(\mathrm{MPa})\end{array}$ & $\begin{array}{c}\text { Ave. stress } \\
(\mathrm{MPa})\end{array}$ & $\mathrm{E}(\mathrm{GPa})$ & Ave. E (GPa) & Strain $50^{*}$ & Stress $50^{* *}$ & $\mathrm{E} 50(\mathrm{GPa})$ \\
\hline R1 & 29.86 & 26.48 & & 0.89 & & 11.71 & 13.24 & 1.13 \\
\hline $\mathrm{R} 2$ & 25.19 & 24.41 & 24.92 & 0.97 & 0.92 & 10.87 & 12.21 & 1.12 \\
\hline R3 & 26.29 & 23.85 & & 0.91 & & 11.90 & 11.93 & 1.00 \\
\hline
\end{tabular}

${ }^{*}$ Strain 50 refers to the strain value when the stress reaches $50 \%$ of the peak stress value. ${ }^{* *}$ Stress 50 refers to $50 \%$ of the peak stress.

specimens conditioned by constant particle size. The evaluation criterion is that the effectiveness can be tested only if the peak stress and E50 under a specific particle weight can consistently reach a comparatively higher level than the alternatives.

Overall, the following main points can be established: (1) a decrease in the peak stress is frequently observed when the particle weight reaches $120 \mathrm{~g}$, while the particle size is less than $1.4 \mathrm{~mm}$, which creates a U-type shape along the particle weightpeak stress curve; (2) comparatively high values of peak stress and modulus are reached when the particle weight is $40 \mathrm{~g}$; (3) setting the particle weight to $160 \mathrm{~g}$ can also lead to favorable values as long as the particle size is less than $1.4 \mathrm{~mm}$.

3.4.2. Effectiveness of the Particle Size. The relationships between particle size and peak stress under different particle weights are plotted in Figure 6. By using the same approach as that described in Section 3.4.1., the curve with the highest peak stress in each group was selected and compared.

Overall, comparatively stronger combinations can be obtained when (1) the particle size is $1.4 \mathrm{~mm}$ and the particle weight is $40 \mathrm{~g}$, (2) the particle size is $1.0 \mathrm{~mm}$ and the particle weight is $80 \mathrm{~g}$, or (3) the particle size is $1.4 \mathrm{~mm}$ and the particle weight is $160 \mathrm{~g}$. If the E50 is simultaneously incorporated for comparison, then the aforementioned first and third combinations can bring about the best mechanical responses.

3.4.3. Optimum Combination of Particle Size and Weight. In Figure 7, the peak stress and secant modulus (E50) of all valid specimens are summarized. The effects of particle weight on each type of particle can be summarized based on the fitted curve of each group; the group is divided by referring to the particle size.

For the peak stress (see Figure 7(a)), the M0.6-group and M1.8-group exhibited a decreasing trend as the particle weight increased; the M1.0-group and M1.4-group exhibited a concave trend as the particle weight increased; and the M2.2-group exhibited a convex trend as the particle weight increased.

For the secant modulus (see Figure 7(b)), the M0.6group and M1.4-group exhibited a concave trend, and the M1.0-group behaved proportionally with the particle weight. Both the M1.8-group and M.2.2-group exhibited a decreasing trend with respect to the elastic modulus, while the secant modulus M.2.2-group exhibited a convex trend.

The conclusion extracted from Figure 7 is that the particle sizes of $1.0 \mathrm{~mm}$ and $1.4 \mathrm{~mm}$ are both favorable for the mechanical responses of the specimens, and this law is especially useful for specimens mixed with $1.4 \mathrm{~mm}$ particles. Additionally, a particle weight of $40 \mathrm{~g}$ is preferable, but sometimes a particle weight of $160 \mathrm{~g}$ can also lead to a considerable result.

Considering the rotation resistance of the bolt during actual installation in the engineering field, the shredding effects of particles should be simultaneously considered. Particles that are $1.0 \mathrm{~mm}$ are relatively small compared with the annulus thickness between a bolt and borehole, so the effective shredding on the plastic film may not be practical. In addition, $160 \mathrm{~g}$ particles can sometimes lead to excessively large rotation resistance because the viscosity of the resin capsule without particles is already large. Therefore, the optimum combination of particle size and weight is $1.4 \mathrm{~mm}$ and $40 \mathrm{~g}$, respectively. It worth mentioning that all ratios in 


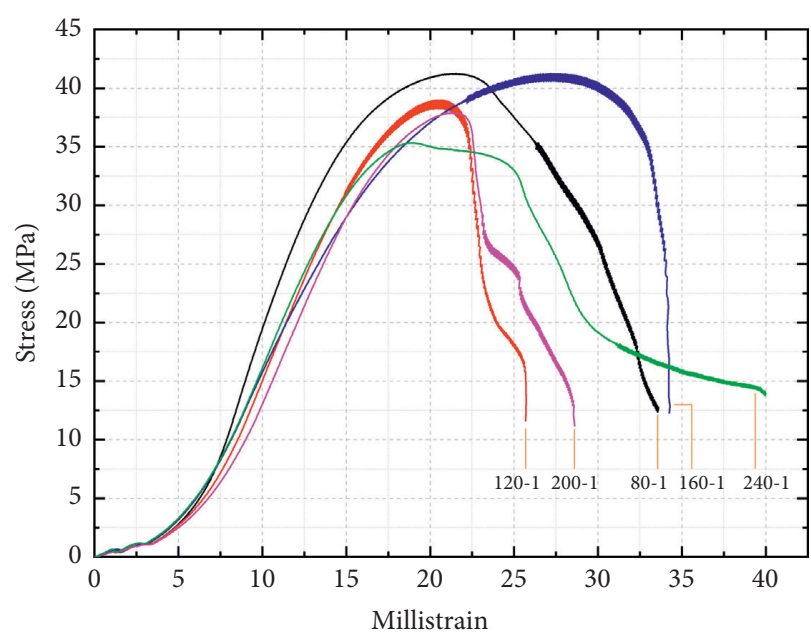

(a)

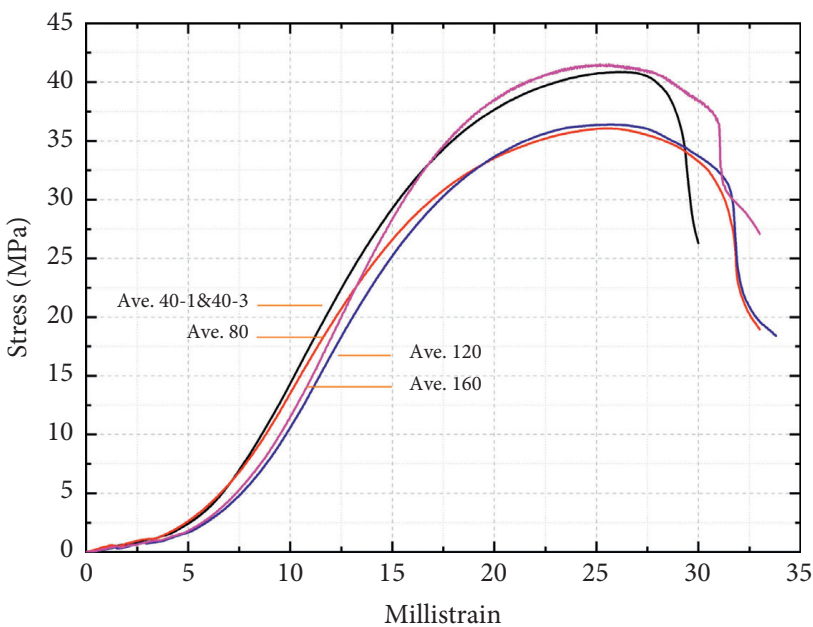

(c)

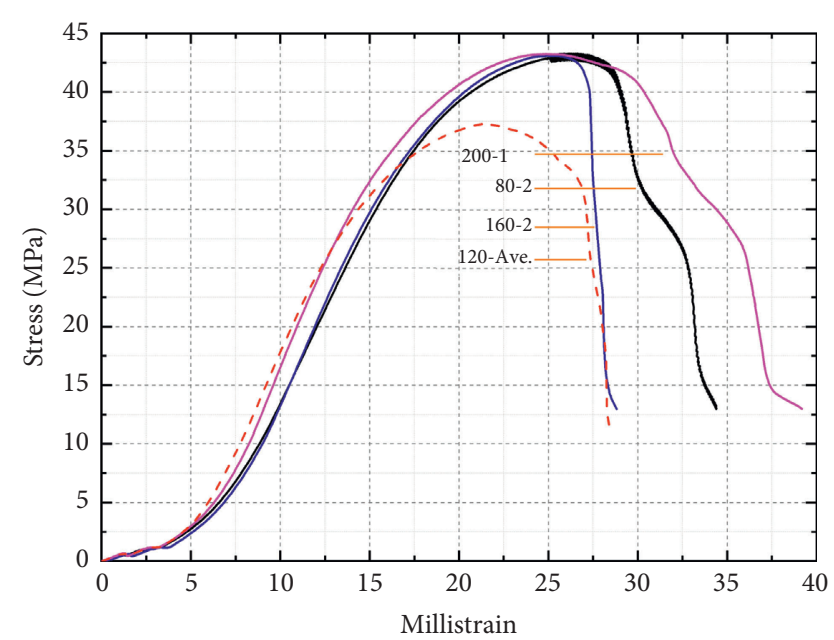

(b)

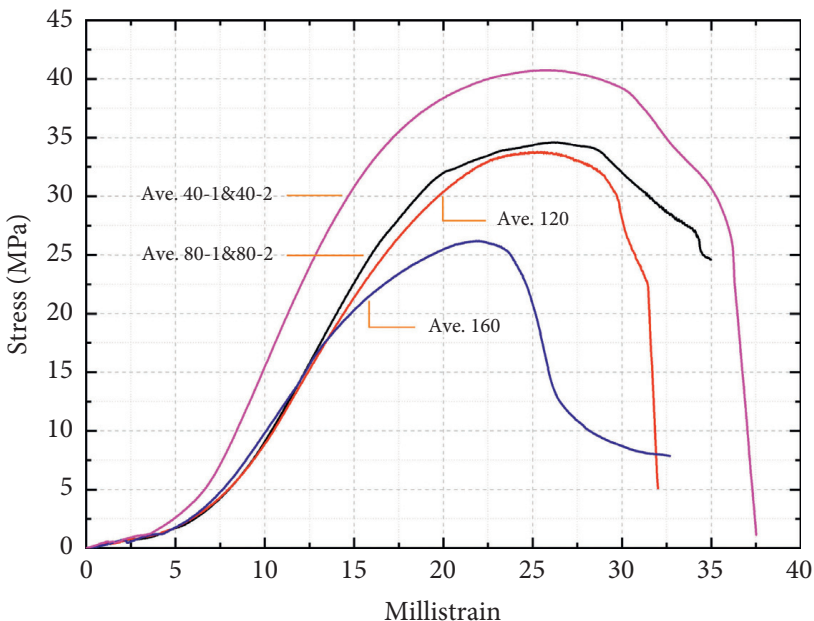

(d)

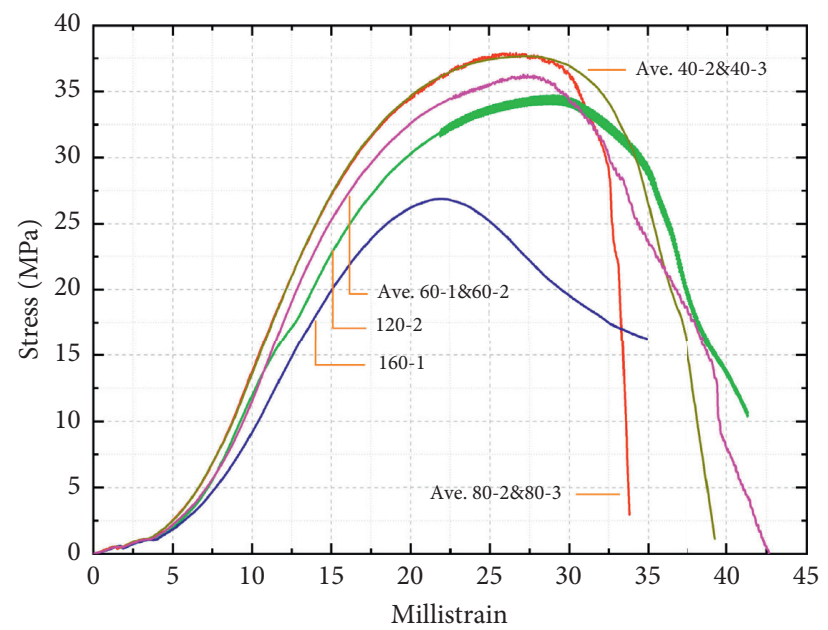

(e)

FIGURE 4: Strain-stress relationships for the specimens mixed with particles of (a) $0.6 \mathrm{~mm}$, (b) $1.0 \mathrm{~mm}$, (c) $1.4 \mathrm{~mm}$, (d) $1.8 \mathrm{~mm}$, and (e) $2.2 \mathrm{~mm}$.

Table 1 should have been equal to 1 at the very beginning, and the reason for the inconsistency was interpreted in Section 2.1. Hence, the ratio should be adjusted accordingly.
For example, for the M1.4-40-3 and M1.4-160-2, the percentage between the "difference" and the "total weight" in Table 1 is $7.27 \%$ and $22.59 \%$, respectively. 


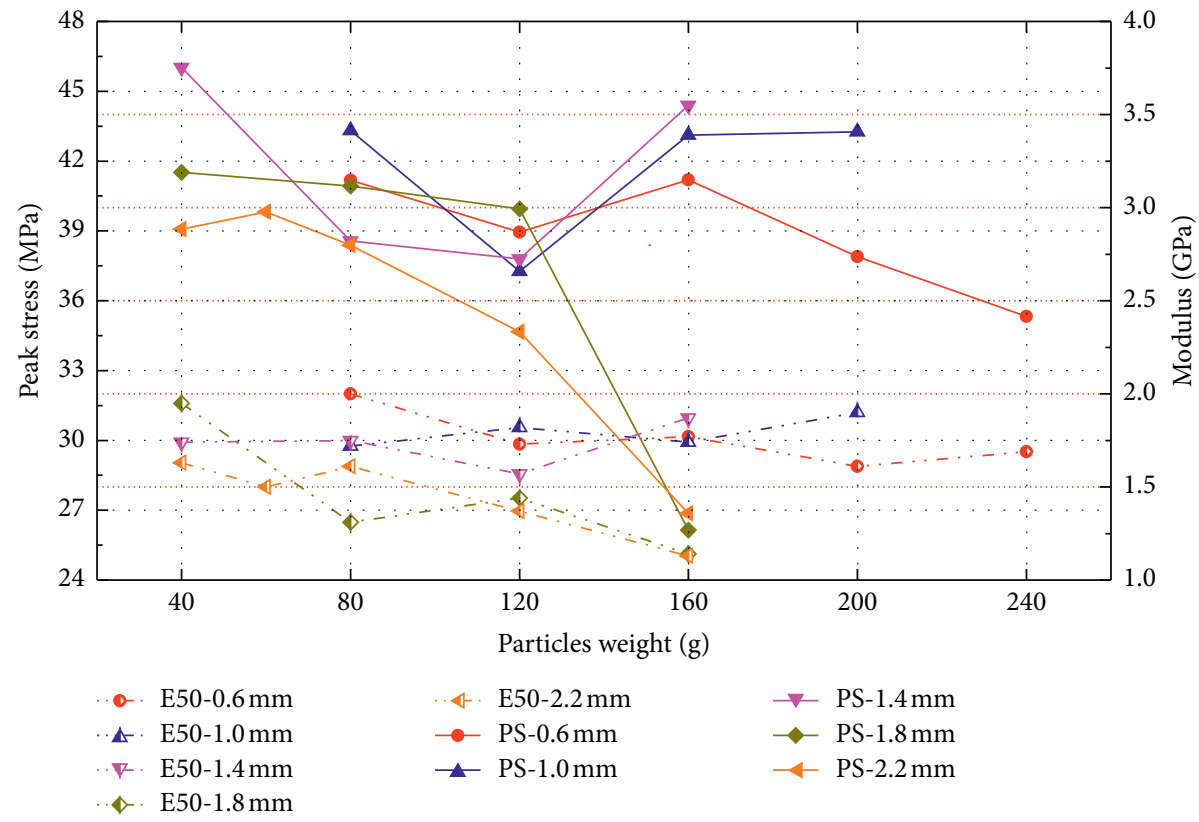

Figure 5: Relationships between the particle weight and peak stress/E50 under various particle sizes.

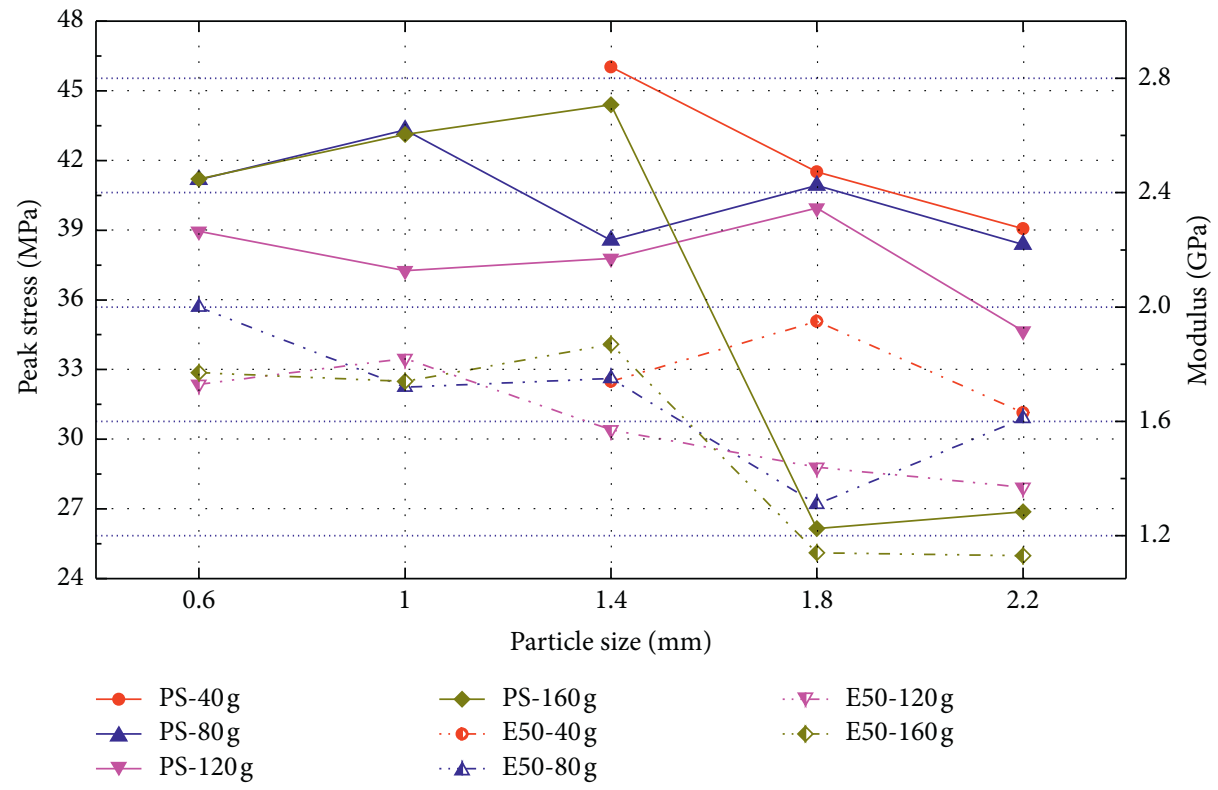

FIGURE 6: Relationships between the particle size and peak stress/E50 under various particle weights.

3.4.4. Failure Patterns for All Specimens. Figure 8 presents the failure patterns of all specimens, and the number range corresponding to Table 1 in the block corresponds to a specific specimen photo in the figure. The failure patterns for the pure resin specimens are mainly dominated by tensile stress with approximate vertical major cracks distributed along the specimens. The failure patterns for the specimens mixed with $0.6 \mathrm{~mm}$ particles are mainly tension (M0.6-1201), shearing (M0.6-160-1, M0.6-200-1, M0.6-240-1), and combined tension and shearing (M0.6-80-1). The failure patterns for the specimens mixed with $1.0 \mathrm{~mm}$ and $1.4 \mathrm{~mm}$ particles are mainly shearing and tension, and no rupture or splitting is observed after failure or during the postpeak force process.

Interestingly, the failure patterns of most specimens exhibit detached morphologies when the particle size is greater than $1.8 \mathrm{~mm}$, as seen in No. 26-30, No. 32-35, No. 3738 , No. 43, and No. 46-47. The actual influencing factor should be the excessively large particles size, which weakens the bonding ability of the resin material and leads to a decrease in the cohesion force and shearing force. Then, the specimen tends to be crushed during the UCS test, and the shearing is the foremost factor causing the splitting of the specimens. 


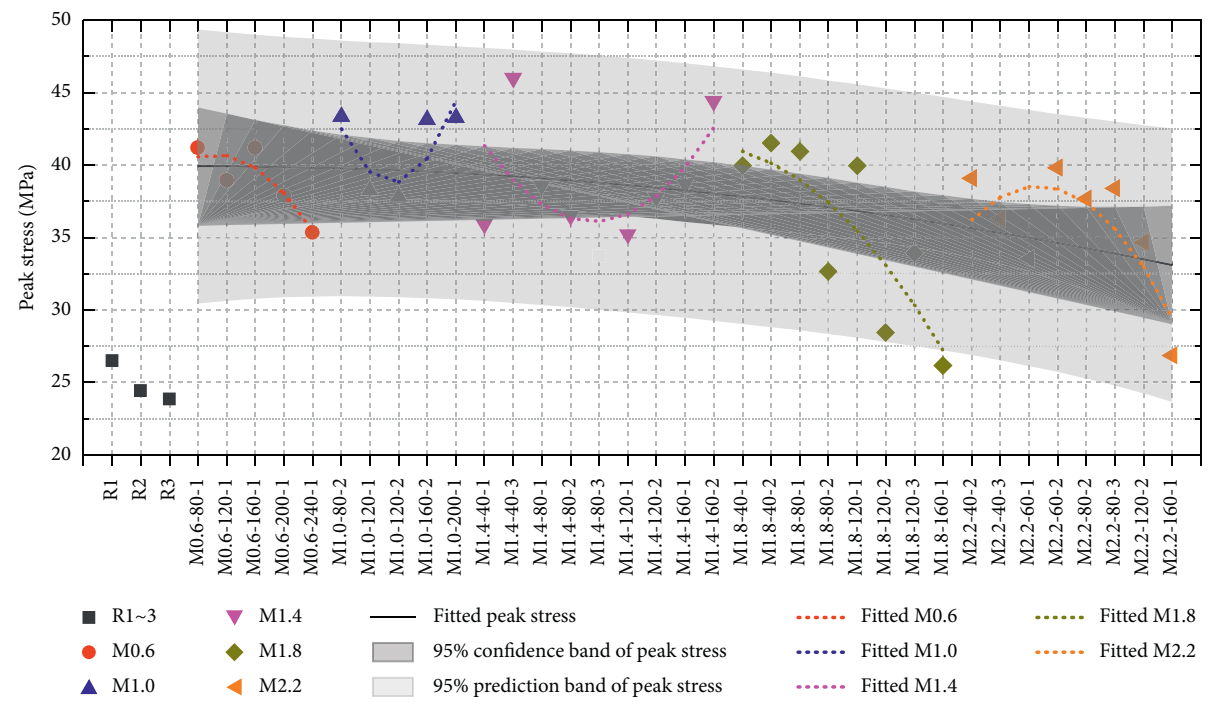

(a)

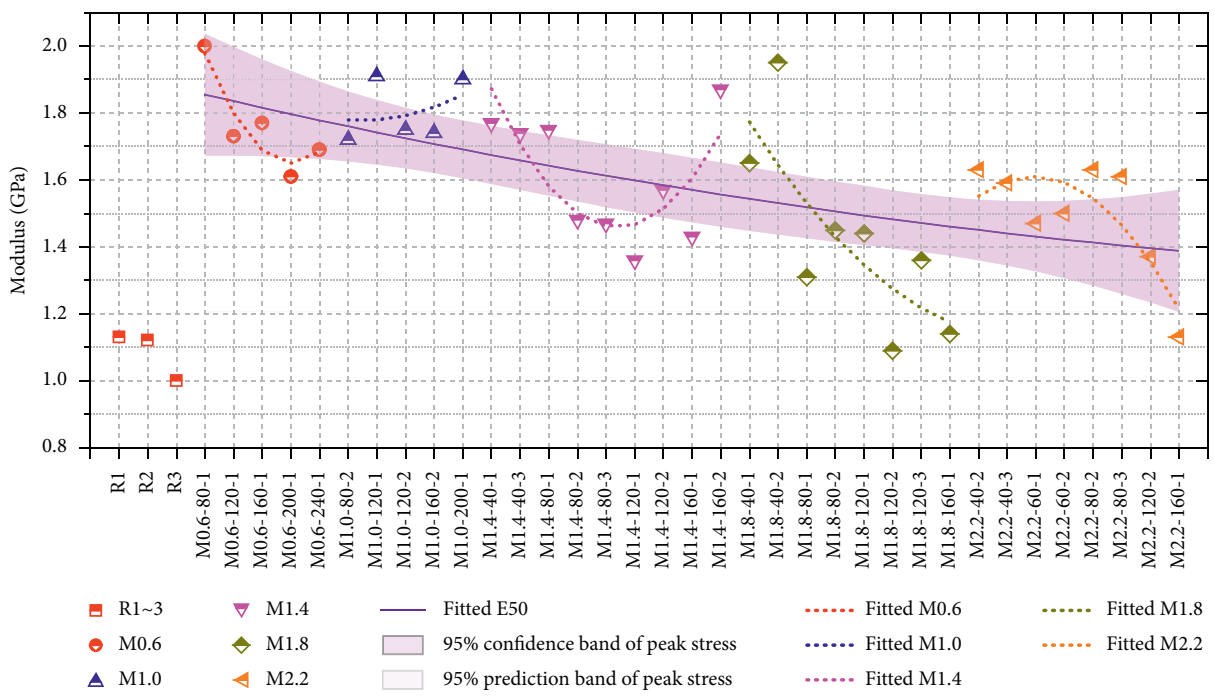

(b)

FIGURE 7: Collection of peak stress and secant modulus (E50) data of all valid specimens: (a) peak stress; (b) secant modulus (E50).

3.5. Verification Based on the Pullout Test. Considering the optimum combination of particle size and weight $(1.4 \mathrm{~mm}$, $40 \mathrm{~g}$ ) and the particles weight percentage (7.27\%) hereinbefore mentioned, additional pullout tests were conducted to further verify such a combination. Pullout test is a widely acknowledged method to examine the bearing capacity of a bolting system, whereby the rock mass is replaced by steel tube. In this test, all of the parameters regarding the coal mine bolt, steel tube, and resin annulus are annotated in Figure 9(a). The packing film of the resin capsule was removed before the test to erase the influence of the gloving; thus, the mechanical improvement of the particles could be independently evaluated. The internal wall of the steel tube was lathed to form rough thread; thereby, the bonding capacity along the resin-tube interface could be strengthened to avoid potential decoupling along this interface during pullout test. Furthermore, a $50 \mathrm{~mm}$ long steel rod was inserted into the steel tube end and was afterwards welded, and then $50 \mathrm{~mm}$ long at the far end of the steel tube was reserved for clamping of the MTS machine during the pullout test; thus, the movement of the bolt would not be restrained.

The relationship between displacement and load is plotted in Figure 9(b), and the bolt tensile behavior is also attached for reference. As can be clearly seen, bolting systems bonded by particles added resin express higher peak load than pure resin bonded bolting system, though the first linear increasing stage for all specimens shows no apparent difference. For resin-particles bonded No. 2 (1), the peak load is $141 \mathrm{kN}(133 \mathrm{kN})$ with a displacement of $19 \mathrm{~mm}$ $(18 \mathrm{~mm})$, whilst, for resin bonded No.1, the values are $110 \mathrm{kN}$ and $10 \mathrm{~mm}$, respectively. A short summary can be drawn here: first, the peak load can be increased by $28 \%$ as least of particles are added into the resin material; second, the resin-particles bonded bolting systems can sustain a more stable postpeak loading state than the resin bonded 


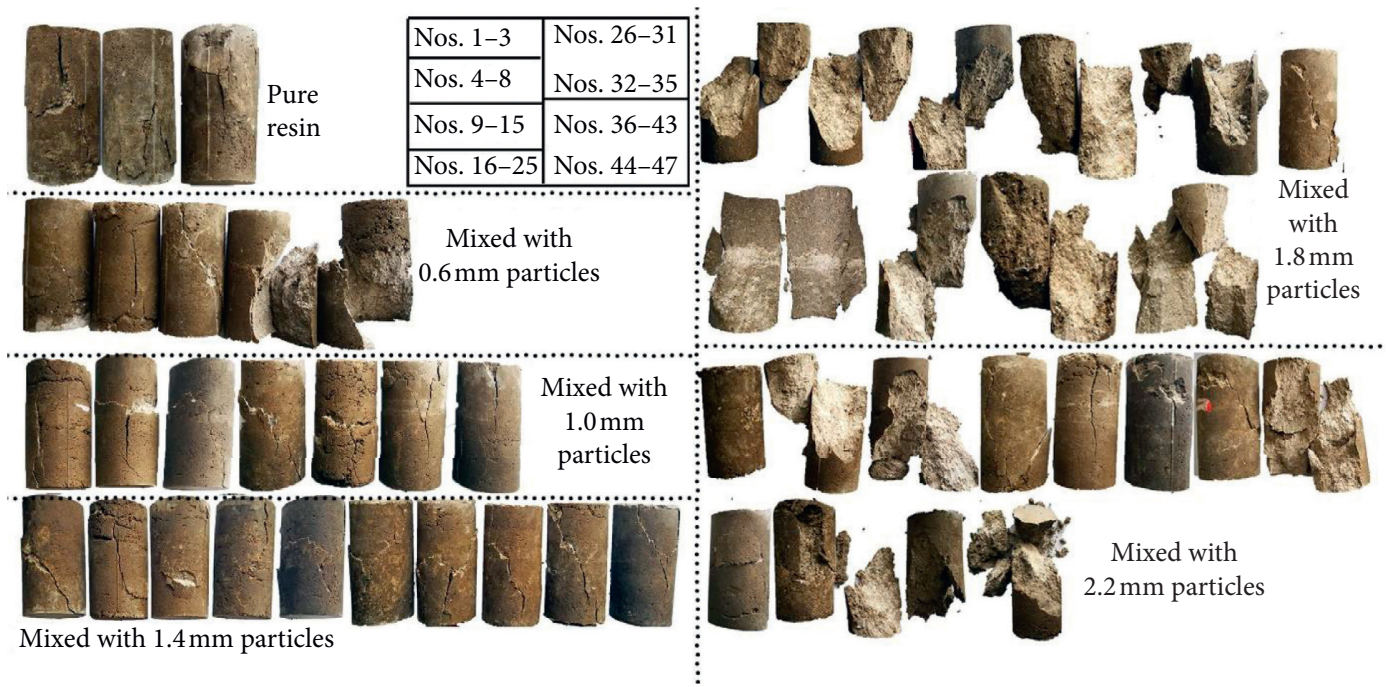

Figure 8: Failure patterns for all specimens. Note that the "No." in the block refers to the "No." in Table 1.

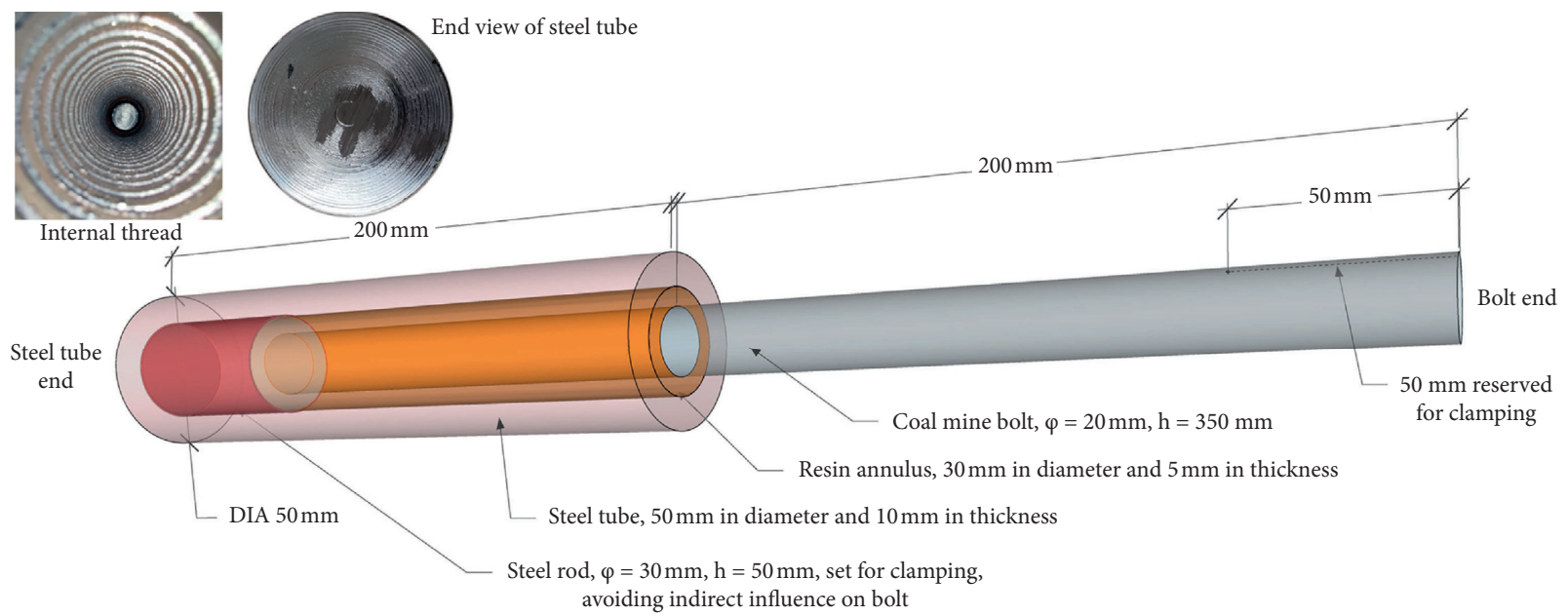

(a)

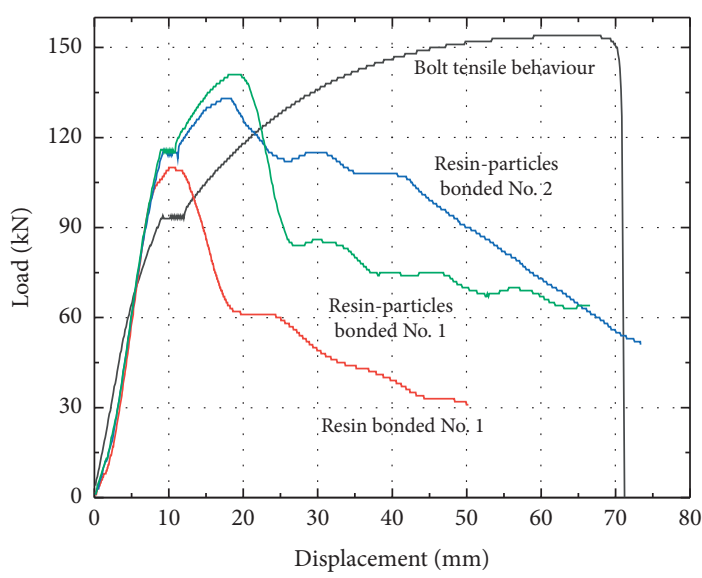

(b)

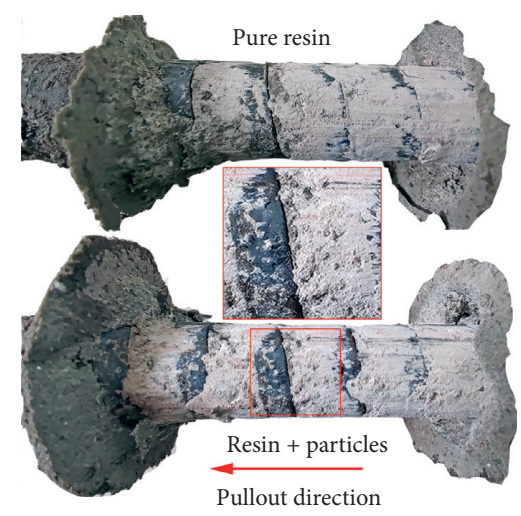

(c)

FIGURE 9: Experimental setup for pullout test and relevant results. (a) Schematic diagram of specimens for pullout test, (b) displacement vs. load for tested specimens, and (c) failure patterns for resin bonded specimen and resin-particles bonded specimen. 
bolting system can do. For instance, the load at a displacement of $50 \mathrm{~mm}$ for the resin bonded bolting system is $31 \mathrm{kN}$, whilst the value for the resin-particles bonded bolting system at a displacement of $50 \mathrm{~mm}$ is $90 \mathrm{kN}$ at most. Undoubtedly, the advantages of the resin-particles bonded bolting system are proved; this is in line with another test conducted by Feng et al. [23].

Figure 9(c) exhibits the failure patterns of the resin bonded specimen (upper one) and resin-particles bonded specimen (lower one). Overall, the exposed bolts are not that different from one another, and scratches along the boltresin interface are clear. However, some particles can be observed on the surface of the lower one (enlarged view), and the exposed bolt area is larger than that of the upper one. The inner mechanism is that the particles are forced to slide during the pullout process of bolt, and the shearing force along the bolt-resin interface is the main power that actuate the particles to rotate and to crush the resin; therefore, the attached resin deposits on the lower one are not very compact. Nonetheless, it is because of the complex interlocking effects of these particles that the peak load of the system can be guaranteed, and the high postpeak load can be sustained; both properties are beneficial to the underground rock support, and the original intention of this study is somewhat achieved.

\section{Discussion}

A main research target in this study was the mechanical properties improvement of resin material after the adulteration of steel particles, with which the optimized particles size and mixture ratio could be determined. However, before drawing a conclusion, the following tips should be concerned. (1) Though the starting point of this study was to remove the gloving problem of bolting system by adding steel particles, the experiments were focused on the mechanical results of standard cylindrical specimens and prepared bolting systems; the main reason was the paper length consideration. Interesting readers can refer to another work of the authors for in-depth understanding of this methodology [23]. (2) The pullout tests were conducted by using steel tube to replace the actual rock, which was not the true reflection of the mechanical properties installed in in situ environment; therefore, the established results should be referred to with caution. Nonetheless, the effectiveness of the particles added bolting system was testified based on the pullout results.

Compared with the existing studies, the improvements are emphasized from following points. (1) The mechanical characteristics of cylindrical resin specimens with steel particles adulterated were analyzed, which were not discussed in the work performed by Cao et al. and Campbell, et al. [10, 15]. (2) Pullout tests on bolts bonded by particlesadulterated resin agent were conducted, which were also different with push test conducted by Chen et al. [24]. Normally, it was believed that pullout test was more reliable than the push test [25]. (3) The optimum combination of particle size and weight was defined to realize the optimum mechanical properties of resin-bonded bolt, which were also not extensively investigated in the existing studies in related with gloving problem, though they raised hypothesis that particles could be a solution to that problem $[24,26]$. Last but not least, the numerical solution for fine particles in soil regarding slope failure or for sanding analysis by fluid flow model could also be referred to for numerical analysis on particles coupling mechanism in this study $[27,28]$, which could be investigated in the future.

\section{Conclusions}

(1) All specimens mixed with particles exhibited greater peak stresses and secant modulus than those of the pure resin specimens. Comparatively higher peak stresses are attained as the particle size varies between $1.0 \mathrm{~mm}$ and $1.4 \mathrm{~mm}$. The secant modulus decreases as the particle size increases.

(2) The optimum combination of particle size and weight in this study is $1.4 \mathrm{~mm}$ and $40 \mathrm{~g}$, respectively; under these conditions, the percentage between the weight of added particles and the total weight of the specimen is $7.27 \%$.

(3) The failure patterns of the pure resin specimens are dominated by tension, and the failure patterns of the specimens mixed with particles are mainly tension, shearing, and combined tension and shearing.

(4) Under the optimum combination of particle size $(1.4 \mathrm{~mm})$, weight $(40 \mathrm{~g})$, and particles weight percentage $(7.27 \%)$, bolting systems were prepared to conduct pullout test. The pullout results indicate that the resin-particles bonded bolting system can have a higher peak load and a more stable postpeak loading state than the resin bonded bolting system can achieve. Therefore, the reliability of adding steel particles into resin capsules is defended, which provides the possibility for relevant field application in the future.

\section{Data Availability}

The raw data used to support the figures in this study are available from the corresponding author upon request.

\section{Conflicts of Interest}

The authors declare that they have no conflicts of interest.

\section{Authors' Contributions}

Xiaowei Feng proposed the idea, performed the experiment, and wrote the manuscript. Tongyang Zhao conducted the experiment and the data analyses. Fei Xue and Wenjie Jiang helped perform the analysis with constructive discussions.

\section{Acknowledgments}

The authors would like to acknowledge the financial support from the National Natural Science Foundation of China 
(51804296), the China Postdoctoral Science Foundation (2019M661989), and the Natural Science Foundation of Zhejiang Province (LQ20E080006).

\section{References}

[1] A. Kılıc, E. Yasar, and A. G. Celik, "Effect of grout properties on the pull-out load capacity of fully grouted rock bolt," Tunnelling and Underground Space Technology, vol. 17, no. 4, pp. 355-362, 2002.

[2] Y. Zheng, C. Chen, T. Liu, D. Song, and F. Meng, "Stability analysis of anti-dip bedding rock slopes locally reinforced by rock bolts," Engineering Geology, vol. 251, pp. 228-240, 2019.

[3] C. C. Li, "Field observations of rock bolts in high stress rock masses," Rock Mechanics and Rock Engineering, vol. 43, no. 4, pp. 491-496, 2010.

[4] R. Schach, K. Garshol, and A. Heltzen, Rock Bolting: A Practical Handbook, The Pennsylvania State University: Pergamon Press, London, UK, 1979.

[5] A. Bobet and H. H. Einstein, "Tunnel reinforcement with rockbolts," Tunnelling \& Underground Space Technology Incorporating Trenchless Technology Research, vol. 26, no. 1, pp. 100-123, 2011.

[6] J. Emery, I. Canbulat, P. Craig, J. Naylor, and A. Sykes, "Development and implementation of spin to stall resin at anglo Americans Australian underground coal operations," International Journal of Mining Science and Technology, vol. 26, no. 1, pp. 161-168, 2016.

[7] R. Campbell and R. J. Mould, "Impacts of gloving and unmixed resin in fully encapsulated roof bolts on geotechnical design assumptions and strata control in coal mines," International Journal of Coal Geology, vol. 64, no. 1, pp. 116-125, 2005.

[8] R. Frith, G. Reed, and M. Mckinnon, "Fundamental principles of an effective reinforcing roof bolting strategy in horizontally layered roof strata and areas of potential improvement," International Journal of Mining Science and Technology, vol. 28, no. 1, pp. 67-77, 2018.

[9] H. C. Pettibone, Avoiding Anchorage Problems with ResinGrouted Roof Bolts, U.S. Bureau of Mines, Washington, DC, USA, RI-9129, 1987.

[10] R. Campbell, R. Mould, and S. Macgregor, "Investigation into the extent and mechanisms of gloving and un-mixed resin in fully encapsulated roof bolts," in Proceedings of the Australasian Institute of Mining and Metallurg, pp. 203-214, Perth, Australia, June 2004.

[11] P. Craig, "Addressing resin loss and gloving issues at a mine with coal roof," in Proceedings of the Australasian Institute of Mining and Metallurgy, pp. 120-128, Melbourne, Australia, November 2012.

[12] S. Ma, N. Aziz, J. Nemcik, and A. Mirzaghorbanali, "The effects of installation procedure on bond characteristics of fully," Grouted Rock Bolts, vol. 40, no. 5, pp. 846-857, 2017.

[13] N. Aziz, P. Craig, A. Mirzaghorbanali, and J. Nemcik, "Factors influencing the quality of encapsulation in rock bolting," Rock Mechanics and Rock Engineering, vol. 49, no. 8, pp. 1-15, 2016.

[14] H. Xin, M. Nijgh, and M. Veljkovic, "Computational homogenization simulation on steel reinforced resin used in the injected bolted connections," Composite Structures, vol. 210, pp. 942-957, 2019.

[15] C. Cao, T. Ren, Y. Zhang, L. Zhang, and F. Wang, "Experimental investigation of the effect of grout with additive in improving ground support," International Journal of Rock Mechanics and Mining Sciences, vol. 85, pp. 52-59, 2016.
[16] A. Campoli, P. Mills, P. Todd, and K. Dever, "Optimizing rebar resin annulus," Mining Engineering, vol. 54, no. 8, pp. 42-44, 2002.

[17] A. Zingano, J. Koppe, J. Costa, and S. Peng, "In-situ tests and numerical sSimulation about the effect of annulus thickness on the resin mixture for fully grouted resin bolt," in Proceedings of 27th international conference on ground control in mining, pp. 284-290, Syd Peng, Morgantown, July 2008.

[18] Z. T. Bieniawski and M. J. Bernede, "Suggested methods for determining the uniaxial compressive strength and deformability of rock materials," International Journal of Rock Mechanics and Mining Science \& Geomechanics Abstracts, vol. 16, no. 2, pp. 138-140, 1979.

[19] B. Shen, J. Shi, and N. Barton, "An approximate nonlinear modified mohr-coulomb shear strength criterion with critical state for intact rocks," Journal of Rock Mechanics and Geotechnical Engineering, vol. 10, no. 4, pp. 645-652, 2018.

[20] X. Feng, N. Zhang, S. Yang, and F. He, "Mechanical response of fully bonded bolts under cyclic load," International Journal of Rock Mechanics and Minings Sciences, vol. 109, pp. 138-154, 2018.

[21] ASTM International, D7012-14e1 Standard Test Methods for Compressive Strength and Elastic Moduli of Intact Rock Core Specimens under Varying States of Stress and Temperatures, ASTM International, West Conshohocken, PA, USA, 2014.

[22] R. Kong, X. T. Feng, X. Zhang, and C. Yang, "Study on crack initiation and damage stress in sandstone under true triaxial compression," International Journal of Rock Mechanics and Mining Sciences, vol. 106, pp. 117-123, 2018.

[23] X. Feng, F. Xue, W. Jiang, M. Wang, and W. Song, "Re-think of solving the gloving problem in bolting systems by adulterating steel particles," Construction and Building Materials, vol. 268, Article ID 121179, 2021.

[24] C. Chen, T. Ren, and C. Cook, "Introducing aggregate into grouting material and its influence on load transfer of the rock bolting system," International Journal of Mining Science and Technology, vol. 24, no. 3, pp. 325-328, 2014.

[25] A. H. Høien, C. C. Li, and N. Zhang, "Pull-out and critical embedment length of grouted rebar rock bolts-mechanisms when approaching and reaching the ultimate load," Rock Mechanics and Rock Engineering, vol. 54, no. 3, pp. 1431-1447, 2021.

[26] Z. Ming, C. Chen, Z. Huaidong et al., "Effect of anchoring force by adding steel aggregate in resin anchoring agent," Journal of China Coal Society, vol. 44, no. 6, pp. 1690-1697, 2019.

[27] Y. Cui, A. Nouri, D. Chan, and E. Rahmati, "A new approach to DEM simulation of sand production," Journal of Petroleum Science and Engineering, vol. 147, pp. 56-67, 2016.

[28] Y. Yin, Y. Cui, Y. Tang, D. Liu, M. Lei, and D. Chan, "Solid-fluid sequentially coupled simulation of internal erosion of soils due to seepage," Granular Matter, vol. 23, no. 2, Article ID 20, 2021. 